\title{
Cancer patients' satisfaction on nursing care
}

\author{
Satisfação do paciente oncológico diante da assistência de enfermagem \\ Satisfacción del paciente oncológico delante de la atención de enfermería
}

Luciana da Conceição Silva ${ }^{1}$, Irena Penha Duprat ${ }^{1}$, Marinho da Silva Correia ${ }^{1}$, Havany Thayany Pereira Ramalho ${ }^{1}$, Josemir de Almeida Lima ${ }^{1}$

Objective: to analyze the satisfaction of cancer patients on nursing care. Methods: descriptive quantitative research with 190 patients receiving outpatient chemotherapy in the High Complexity Centre in Oncology, through a questionnaire. Results: 185 respondents (97.4\%; 95.0\% CI 94.7 to 99.9) said they were always satisfied with the care provided, however, less than a third assessed that charisma (34.2\%; 95.0\% CI 27.4 to 39.5), respect for their decisions (31.6\%; 95.0\% CI 24.7 to 37.4 ) and clear communication (26.3\%, CI 20.0 to 31.1) were decisive factors for their satisfaction. Conclusion: the study revealed an excellent level of patient satisfaction on nursing care, although some factors considered by users as decisive for the identification of this feeling have not been significantly identified. This justifies the need for critical reflection, in the professional's view, that fosters the implementation of changes and to better meet the expectations and needs of the patient. Descriptors: Patient Satisfaction; Nursing; Humanization of Assistance.

Objetivo: analisar a satisfação do paciente oncológico diante da assistência de enfermagem. Métodos: pesquisa descritiva, quantitativa, com 190 pacientes em tratamento quimioterápico ambulatorial no Centro de Alta Complexidade em Oncologia, através de questionário. Resultados: 185 entrevistados (97,4\%; IC 95,0\% 94,7-99,9) disseram sempre estar satisfeitos com a assistência prestada, no entanto, menos de um terço avaliaram que carisma (34,2\%; IC 95,0 \% 27,4-39,5), respeito as suas decisões (31,6\%; IC 95,0\% 24,7-37,4) e comunicação clara (26,3\%; IC 20,0-31,1) são fatores decisivos para sua satisfação. Conclusão: o estudo revelou um excelente nível de satisfação dos pacientes diante da assistência de enfermagem, embora alguns fatores considerados pelos usuários como determinantes para a identificação deste sentimento não tenham sido apontados de forma expressiva, justificando a necessidade de uma reflexão crítica, na ótica do profissional, que favoreça a implantação de mudanças e, consequentemente, melhor atendam às expectativas e necessidades do paciente.

Descritores: Satisfação do Paciente; Enfermagem; Humanização da Assistência.

Objetivo: analizar la satisfacción del paciente oncológico en la atención de enfermería. Métodos: estudio descriptivo, cuantitativo, con 190 pacientes que reciben quimioterapia ambulatoria en el Centro de Alta Complejidad en Oncología, a través de cuestionario. Resultados: 185 encuestados (97,4\%; 95,0\% IC 94,7-99,9) dijeron siempre quedarse satisfechos con la atención recibida, sin embargo, menos de un tercio evaluaron que carisma (34,2\%; 95 0\% 27,4-39,5), respetar sus decisiones (31,6\%; IC del 95,0\% 24,7-37,4) y comunicación clara $(26.3 \%$, IC 20,0-31, 1) son factores decisivos para satisfacción. Conclusión: el estudio reveló excelente nivel de satisfacción de pacientes en la atención de enfermería, aunque algunos factores considerados por usuarios como decisivas para identificación de este sentimiento, no ha sido identificado de manera significativa, lo que justifica la necesidad de reflexión crítica, en la opinión del profesional, que favorezca la implementación de cambios y, consecuentemente, mejor atención a las expectativas y necesidades del paciente.

Descriptores: Satisfacción del Paciente; Enfermería; Humanización de la Atención.

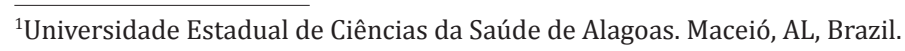

Corresponding author: Irena Penha Duprat

Rua Paulina Maria Mendonça, 618, Jatiuca. CEP: 57035-557. Maceió, AL, Brazil. E-mail: irenap@ig.com.br 


\section{Introduction}

The incidence of cancer has grown in Brazil and around the world in a rate that accompanies the aging population deriving from increased life expectancy. It is a direct result of the great global transformations of recent decades, which changed the health status of people due to rapid urbanization, new lifestyles and new patterns of consumption ${ }^{(1)}$.

For the year 2015, the Brazilian National Cancer Institute indicates the occurrence of about 576,000 new cases of cancer, including non-melanoma skin cases, reinforcing the magnitude of the problem of this disease in the country ${ }^{(2)}$.

Each person has unique features to cope with cancer, because of their beliefs, values, culture, prejudice and way of seeing the world, although there are similar aspects in living with cancer. Receiving a diagnosis causes various feelings, anxieties and concerns in people, precisely because the future becomes obscure, often with no prospects, since the threat of life seems to become closer when the diagnosis is instituted ${ }^{(3)}$. Establishing a relationship of acceptance and trust between professional and patient, which allows patients to express themselves through dialogue is critical. This bond contributes to their rehabilitation in all aspects, enhancing their quality of life, maintaining their autonomy, self-care ability, family and social life ${ }^{(4)}$.

To provide quality care to cancer patients, health professionals, at all levels of care, must have technical and scientific knowledge and skills in interpersonal relationships. In this scenario, nursing, whose essence is the art of care, is entirely linked to humanization, and it is impossible to deal with a 'human being' without 'being' human (especially cancer patients). Humanization of health services involves changing the very way the service user is understood.

The way to humanize care is characterized by nursing professionals as a practice based in a professional/patient relationship, which includes personal characteristics by looking at the needs, through dialogue, attentive listening, holistic vision, empathy, moral and ethical values, and by including subjective issues such as love, thinking, appreciation of the being, link establishment, attention, willingness, understanding and caring ${ }^{(5)}$.

It is important to remember that care for patients with cancer also covers all care provided to the patient and family in their time of anxiety, insecurity, uncertainty, doubts, before their clinical condition and the imminence of death. The nurse's role is critical to the control of fear, weakness, anguish and difficulties encountered by nursing care, promoting psychosocial support, comfort and care needed to this context ${ }^{(6)}$.

In this light, the nurse must have characteristics and skills so that there is commitment to the patient in order to meet the care requirements necessary for oncology care, thus impacting the quality of care. The professional experience and specialized skills are aspects that should be rethought in the current context of hiring nurses to work in oncology ${ }^{(7)}$.

From another angle, it is essential to evaluate the service by patients, putting on display their perceptions. In this sense, listening to what patients have to report on the quality of care provided and about their satisfaction can be a chance to build an outcome indicator ${ }^{(8-9)}$ with which it is acquired information that benefit the organization of these services as they allow the implementation of changes through valuation and appreciation of their needs and expectations $^{(9)}$.

Accordingly, there is the need to build a study from the viewpoint of cancer patients with the aim of analyzing their satisfaction on the nursing staff assistance.

\section{Method}

Descriptive, quantitative research, developed at the High Complexity Centre in Oncology, located at the University Hospital Prof. Alberto Antunes in 
Maceio/AL. It is an outpatient treatment unit for cancer patients, which currently attends children and adults with solid malignant tumors.

The target population for this study consisted of 388 patients undergoing chemotherapy, registered in the institution's information system. The calculation of sample size was estimated at 190 individuals in outpatient treatment, considering a maximum percentage of continuous treatment during data collection of $40.0 \%$, and a significance level of $5.0 \%$.

Cancer patients aged 18 years or older who agreed to participate by signing the Informed Consent Form, registered in the Information System of the High Complexity Centre in Oncology and who were undergoing continuous and regular chemotherapy were included.

Cancer patients under 18 years old, those who refused to participate and those who were in another type of cancer treatment were excluded.

Data were collected in the months of September and October 2014 through a questionnaire, which was applied on a regular basis and in accordance with the schedule provided by the institution to patients who were receiving outpatient chemotherapy. The variables studied included demographic characteristics such as gender, age, marital status and education and were related to the perceptions of cancer patients on humanization of care; host; meeting of needs; confidence and satisfaction on nursing care.

For making the database, it was used Excel 2007 software for Windows Professional, and for data analysis, the statistical program BioEstat, version 5.3. A descriptive analysis was performed and its Exact Confidence Intervals (CI 95.0\%) were calculated for the specific estimates of the sample.

Data collection was preceded by the consideration and approval of the research project by the Ethics Research Committee of the State University of Health Sciences of Alagoas, under Protocol no. 1995.

\section{Results}

The distribution of the 190 patients according to sex, marital status, ethnicity, and education revealed a predominance of females $(63.1 \%$; $95.0 \%$ CI 56.3- 68.4). Most were married (51.0\%, $95.0 \%$ CI 43.7 - 6.3) and mulatto (57.9\%; 95.0\% CI 51.1 - 63.7). Nearly half of the study population $(47.3 \%$; $95.0 \%$ CI 40.5 to 53.7 ) has not reached high school.

Table 1 - Humanization of care by nursing staff to patients undergoing chemotherapy

\begin{tabular}{lcc}
\hline Variables & $\mathbf{n ( \% )}$ & CI(95\%) \\
\hline Host and quality care & $95(50)$ & $43.2-55.8$ \\
Respect & $20(10.5)$ & $6.3-14.2$ \\
Communication at the time of treatment & $35(18.4)$ & $13.2-22.6$ \\
Attention & $30(15.8)$ & $11.1-19.5$ \\
Comfort in attending & $20(10.5)$ & $6.3-14.2$ \\
Commitment & $25(13.2)$ & $8.4-17.4$ \\
Equal treatment to other patients & $15(7.9)$ & $4.2-11.1$ \\
\hline
\end{tabular}

Table 1 shows attitudes and behaviors that express humanization in the actions of nursing professionals. This question admitted more than one answer, since it may be perceived by the patient at various times during their chemotherapy. It was noticed that 95 participants $(50.0 \%$; $95.0 \%$ CI 43.2 to 55.8) understood the humanization through host and quality care. Less than $20.0 \%$ of respondents mentioned respect, communication at the time of treatment, attention, comfort and commitment by the team; only 15 patients (7.9\%; 95.0\% CI 4.2 - 11.1) thought that humanization is also expressed in equal treatment with other patients. 
Table 2 - Patients' opinion as the frequency with which they feel welcomed, have their needs met, feel confidence and satisfaction on nursing care

\begin{tabular}{lcc}
\hline Variables & $\mathbf{n ( \% )}$ & CI(95\%) \\
\hline Host from nursing professionals & & \\
Always & $170(89.5)$ & $85.3-92.6$ \\
Often & $20(10.5)$ & $6.3-14.2$ \\
Not always & - & - \\
Never & - & - \\
Care needs met by the nursing team & & \\
Always & $175(92.1)$ & $87.9-95.3$ \\
Often & $15(7.9)$ & $4.2-11.1$ \\
Not always & - & - \\
Never & - & - \\
Confidence in the team who provides & & \\
services & & - \\
Always & $180(94.7)$ & $91.1-97.4$ \\
Often & $10(5.3)$ & $2.6-7.4$ \\
Not always & - & - \\
Never & - & - \\
Satisfaction with the care provided by & & $0.5-4.2$ \\
the nursing team & & - \\
Always & $185(97.4)$ & $94.7-99.9$ \\
Often & $5(2.6)$ & - \\
Not always & - & \\
Never & - & \\
\hline & & \\
\hline
\end{tabular}

Table 2 shows, in the opinion of patients, the frequency with which they feel welcomed, have their needs met, feel confidence and satisfaction on nursing care.

It was found that most respondents always felt supported (89.5\%; 95.0\% CI 85.3 - 92.6) and always had their requests met (92.1\%; 95.0\% CI 87.9 - 95.3). It was also observed that professionals always gave confidence to the patient, reflection of most of the answers given by them (94.7\%; 95.0\% CI 91.1 97.4). With regard to patient satisfaction with the care provided by the nursing staff, almost all of the subjects (97.4\%; 95.0\% CI 94.7 - 99.9) said always being satisfied.

Among the factors that favored the patient's satisfaction with the nursing staff, varied responses were given in the survey, as this feeling can be realized in more than one attitude performed by professional. Of the 190 patients interviewed, 100 respondents (52.6\%; 95.0\% CI 45.3 - 58.4) showed that the receptiveness by the team was crucial to their satisfaction, and less than a third of the participants evaluated that charisma (34.2\%; 95.0\% CI 27.4 39.5), respect for their decisions (31.6\%; $95.0 \% \mathrm{CI}$ 24.7 to 37.4 ) and clear communication $(26.3 \% 95.0 \%$ CI 20,0-1,1) were also deciding factors.

\section{Discussion}

Results show a low frequency of responses $(\leq 50.0 \%)$ with regard to the way the patient undergoing cancer treatment perceives attitudes and behaviors that express humanization in the actions of nursing professionals. This corroborates a national study in which aspects like sympathy, understanding of timing, interest, respect, quality service and responsibility were perceived to be facilitators of humanization of assistance, however, only by a maximum of $50.0 \%$ of respondents, too ${ }^{(10)}$.

In contrast, two other studies showed most relevant results regarding the importance of the professional caregiver being present, discuss, provide information and be available for better interaction in the care process. This interaction, besides promoting comfort, was better understood as a possibility of creating empathy ties, wrapped in trust, respect, affection and attention ${ }^{(11-12)}$.

It must be remembered that the nursing practice in oncology is held in various health care settings, including homes, community, acute care and rehabilitation centers. It is up to the nursing professional to take a humanized behavior, that is, to consider the human being as an individual who belongs to society, endowed with knowledge, spirituality, culture and feelings ${ }^{(13)}$.

Demonstrations of humanized attitudes become synonymous with care and it is worth bringing 
to mind that the nursing care needs to be based not only on technical and scientific knowledge, but also in the interaction between the triad cared person, family and professional. Therefore, it is necessary that the nursing professional's intentionality is driven by the responsibility of maintaining the care goals ${ }^{(14)}$.

The survey also revealed that almost all of the respondents always felt welcomed by the nursing team, always felt supported and felt that professionals always transmitted confidence, confirming literature previous findings where the relationship of trust, availability of professionals and reception proved satisfactory ${ }^{(11-12,15)}$.

Nursing is one of the health professions whose focus is the care for human beings, meeting the needs of each patient with a quality host, able to give confidence to the assisted patient through their services ${ }^{(10)}$. From an active listening by the caregiver, there is an understanding and appreciation of the patient's ideas, whose gained trust enables the awareness of his emotions, making the proper care and improving treatment adherence ${ }^{(13)}$.

Another favorable point in this study was the excellent level of satisfaction (97.4\%) expressed by participants regarding the care provided by the nursing staff. A similar result was observed in international survey of 183 patients, which aimed to determine the level of satisfaction of public hospitals users in relation to the care provided by nursing. In this case, there was an overall index of satisfaction with the quality of care of $92.9 \%{ }^{(16)}$.

It is important to note that health services shall have as intrinsic characteristic the search for quality, since they exist to serve patients. In view of that, it is imperative to meet their needs and achieve the highest level of satisfaction with the care provided. Aiming to meet the needs of health service users consists of a way to measure the quality of care provided by professionals in this sector, although the quality of care still remains a major concern in health ${ }^{(17)}$.

In this context the factors that favored cancer patients' satisfaction with the nursing staff at the service were identified. Although marked by a little more than half of respondents, the results showed that to obtain satisfactory rates it is necessary, above all, that the team provides a good host. But it was realized that effective and objective communication endowed with clarity, charisma and respect of professionals to their decisions are also crucial in identifying this feeling.

These and other factors could also be identified in a study related to user satisfaction on nursing care in a health service, in which users have expressed a high degree of satisfaction with the care provided, thus highlighting, respect, consideration, listening , comprehension, host and kindness on the part of the professionals who attended them ${ }^{(18)}$.

The pursuit of customer satisfaction is present throughout the process of acquisition or use of products/services. Customers, users and those who have the power to influence them determine the last word and the extent to which a product meets or not their needs and is able to meet their expectations. Customer expectations are quality standards because customers assess the quality of service by comparing what they want or expect ${ }^{(19)}$, that is, user satisfaction occurs when their needs and expectations are met, so that their perceptions and the expected results are achieved. These expectations are usually related to several factors, including communication and information, emotional support, participation and involvement, control of decision by the patient, as well as interpersonal relationships and expertise ${ }^{(20)}$.

\section{Conclusion}

This survey revealed an excellent level of satisfaction of patients undergoing chemotherapy attended at the High Complexity Centre in Oncology of Alagoas regarding nursing care. Although respondents were asked to give one or more responses that represented the factors considered 
crucial for the identification of this feeling, there was an unequal proportion of the alternatives indicated by them. This justifies the need for a critical reflection by professionals, in order to better meet customer needs and expectations, promoting this awareness, especially through the achievement of expected results.

The findings also showed that almost all the respondents always felt welcomed by the nursing team, always felt supported and felt that professionals always transmitted confidence.

Regarding the limitations of the study, it is noted that the presentation of results was obtained from the perspective of participants; however, further research may be carried out considering the perception of the nursing team on cancer patients' and their family's needs and expectations.

\section{Collaborations}

Silva LC, Correia MS and Ramalho HTP contributed to the organization, analysis, data interpretation and writing of the article. Duprat IP contributed to monitoring, adjustment and review at all stages. Lima JA contributed in the analysis and interpretation of data.

\section{Referências}

1. Instituto Nacional do Câncer José de Alencar Gomes da Silva (INCA). A situação do câncer no Brasil. Rio de Janeiro: INCA; 2006.

2. Instituto Nacional do Câncer José de Alencar Gomes da Silva (INCA). Coordenação de Prevenção e Vigilância. Estimativa 2014: Incidência de Câncer no Brasil. Rio de Janeiro: INCA; 2014.

3. Salci MA, Marcon SS. Enfrentamento do câncer em família. Texto Contexto Enferm. 2011; 20(Esp):178-86.

4. Rodrigues FSS, Polidori MM. Enfrentamento e Resiliência de Pacientes em Tratamento Quimioterápico e seus Familiares. Rev Bras Cancerol. 2012; 58(4):619-27.
5. Chernicharo IM, Silva FD, Ferreira MA. Caracterização do termo humanização na assistência por profissionais de enfermagem. Esc Anna Nery. 2014; 18(1):156-62.

6. Silva MEDC, Silva LDC, Dantas ALB, Araújo DOR, Duarte IS, Sousa JFM. Nursing care to cancer patients in the hospital. Rev Enferm UFPI. 2013; 2(5):69-75.

7. Santos FC, Camelo SHH, Laus AM, Leal LA. El enfermero de unidades hospitalarias oncológicas: perfil y capacitación profesional. Enferm Global. 2015; 37(5):313-24.

8. Freitas JS, Silva AEBC, Minamisava R, Bezerra ALQ, Sousa MRG. Quality of nursing care and satisfaction of patients attended at a teaching hospital. Rev Latino-Am Enfermagem. 2014; 22(3):454-60.

9. Lyu H, Wick EC, Housman M, Freischlag JA, Makary MA. Patient satisfaction as a possible indicator of quality surgical care. JAMA Surg. 2013; 148(4):362-7.

10. Brito NTG, Carvalho RA. Humanization according to cancer patients with extended hospitalization periods. Einstein. 2010; 8(2 Pt 1):221-7.

11. Ponte KMA, Silva LF. Cuidados de enfermagem a mulheres com infarto do miocárdio: promoção do conforto sociocultural pela pesquisa-cuidado. Rev Enferm UERJ. 2014; 22(6):808-14.

12. Dorigan GH, Guirardello EB. Patient satisfaction in a gastroenterology unit. Acta Paul Enferm. 2010; 23(4):500-5.

13. Almeida CSL, Sales CA, Marcon SS. The existence of nursing in caring for terminally ills'life: a phenomenological study. Rev Esc Enferm USP. 2014; 48(1):34-40.

14. Kluser SR, Terra MG, Noal HC, Lacchini AJ, Padoin SMM. Vivência de uma equipe de enfermagem acerca do cuidado aos pacientes com câncer. Rev Rene. 2011; 12(1):166-72.

15. Lafaiete RS, Motta MCS, Villa TCS. Satisfação dos usuários no programa de controle da tuberculose de um município do Rio de Janeiro, Brasil. Rev Latino-Am Enfermagem. 2011; 19(3):508-14.

16. Barragán JA, Pedraza YD, Rincón MR. Calidad percibida de la atención de enfermería por usuarios hospitalizados, Tunja, 2011. Rev Fac Nac Salud Pública. 2013; 31(2):187-93. 
17. Gonçalves JR, Veras FEL, Matos ACM, Lima ISA. Avaliação da satisfação dos pacientes submetidos à intervenção fisioterapêutica no município de Campo Maior, PI. Fisioter Mov. 2011; 24(1):47-56.

18. Barbosa TLA, Gomes LMX, Dias OV. O pré-natal realizado pelo enfermeiro: a satisfação das gestantes. Cogitare Enferm. 2011; 16(1):29-35.
19. Santos FK, Silva MVG, Gomes AMT. Conhecendo as formas de cuidar dos enfermeiros de centro cirúrgico - uma construção a partir da teoria fundamentada nos dados. Texto Contexto Enferm. 2014; 23(3):696-703.

20. Cruz WBS, Melleiro MM. Assessment levels of the user's satisfaction in a private hospital. Rev Esc Enferm USP. 2010; 44(1):145-51. 